\title{
Cubitus varus deformity in young adults, Correction by rigidly fixed lateral closing wedge osteotomy
}

\author{
Snobar Gul ${ }^{1}$, Younis Kamal ${ }^{2 *}$, Javaid Ahmed ${ }^{3}$, Murtaza Fazal Ali ${ }^{4}$, Bilal Ahmad Lone ${ }^{5}$ \\ ${ }^{1}$ Demonstrator, ${ }^{\mathbf{2}}$ Assistant Professor, ${ }^{3}$ Ragistrar, ${ }^{4}$ Consultant Ragistrar, ${ }^{1}$ Dept. of Anatomy, ${ }^{2-5}$ Dept. of Orthopaedics, GMC, Srinagar, \\ Jammu \& Kashmir, India
}

*Corresponding Author: Younis Kamal

Email: kdryounis@gmail.com

\begin{abstract}
Neglected or poorly managed elbow trauma in developing countries often present as complex deformities of elbow in adolescents and young adults. Mostly deformities are being corrected for functional and/or cosmetic reasons. Same is the case with neglected post-traumatic cubitus varus deformity in young adults both male and female. Often these deformities are being corrected before the skeletal maturity even in developing countries now a day's except few underprivileged whose deformities are left unaddressed till skeletal maturity. This is a retrospective study which was conducted on 14 young adults with post-traumatic cubitus varus deformity who underwent corrective surgery in our hospital during last three years. The mean age of patients was 24.4 years and mean time since injury to correction of deformity was 18 years. The male and female ratio was equal. Our mean follow up was 21.42 months. The mean cubitus varus deformity of $-15.42^{0}$ was corrected to a mean of cubitus valgus of $11.71^{0}$ and our mean valgus angle on normal side was $13^{0}$. The lateral condyle prominence was reduced from mean of 5.56 to mean of -13.14 percent. Neglected traumatic deformity like cubitus varus must be dealt early to avoid complications. Lateral closing wedge osteotomy with rigid fixation of lateral column of distal humerus for correction of cubitus varus in young skeletally mature adults has promising results in achieving the correction of deformity, timely union and preserving the elbow arc of motion.
\end{abstract}

Keywords: Cubitus varus, Young adults, Lateral closing wedge osteotomy.

\section{Introduction}

Mismanaged or poorly managed paediatric supracondylar humerus fractures are most common cause for cubitus varus deformity of elbow. Neglected or poorly managed elbow trauma in developing countries often present as complex deformities of elbow in adolescents and young adults. Mostly deformities are being corrected for functional and/or cosmetic reasons. Same is the case with neglected posttraumatic cubitus varus deformity in young adults both male and female. Ulnar nerve irritation or posterio-medial instability may be the indications to correct the deformity but most common indication for correction of the deformity is cosmetic appearance. Wearing sleeveless or short sleeves becomes unacceptable in young females with cubitus varus deformity. While as recruitment in various physically demanding jobs like defence or sports force the young males to go for correction of this deformity.

Often these deformities are being corrected before the skeletal maturity even in developing countries now a day's except few underprivileged whose deformities are left unaddressed till skeletal maturity. Surgical techniques to correct cubits varus deformity in young adults include lateral invaginated peg osteotomy, ${ }^{3}$ lateral closing wedge osteotomy ${ }^{1,2}$ and medial open wedge osteotomy. ${ }^{4}$ More complex procedures include dome osteotomy, ${ }^{5-7}$ pentalateral osteotomy, ${ }^{8}$ three-dimensional osteotomy, ${ }^{9,10}$ and step-cut translational osteotomy ${ }^{11}$ to correct this cosmetic deformity.

Lateral oblique closing wedge osteotomy has advantage of three dimensional correction and high rate of union. But fixation of such osteotomy is of paramount importance in young adults than in paediatric age group in view of less healing power and postoperative stiffness in these patients compared to paediatric age group. Previous research articles on corrective osteotomy of cubits varus deformity has been done on either on young ${ }^{1,2}$ or on patients with mixed age group. ${ }^{8,11,12}$ Some other studies have used different fixation techniques to correct this deformity. ${ }^{7,9}$ To overcome these post operative complications in young adults various authors have used different methods of fixations devices to achieve osteotomy site union as well as good range of motion. Healing of distal humeral osteotomy in children is achieved within 3 to 6 weeks due to strong healing power. ${ }^{1}$ Healing of osteotomy in this region in adults takes more than 3 months ${ }^{11,13}$ and reported non union and delayed union in distal humerus fractures is as much as $10 \% .{ }^{14}$ Osteotomy site compression and rigid fixation of osteotomy using plate and screws either on lateral column or both column of distal humerus helps us achieve both union as well good range of motion after such osteotomy.

We here present our results of lateral closing wedge osteotomy and rigid fixation of osteotomy for correction of cubitus varus in young adults.

\section{Materials and Methods}

This study was conducted department of orthopaedics GMC Anantnag, lone referral centre of south Kashmir. This hospital caters population of 3 million people.

This is a retrospective study which was conducted on 14 young adults with posttraumatic cubitus varus deformity who underwent corrective surgery in this hospital during last three years. All relevant data bout sociodemographic profile, preoperative state of deformity, operative details were collected from record section pf the hospital. The data was analysed regarding various patient factors like age, sex, 

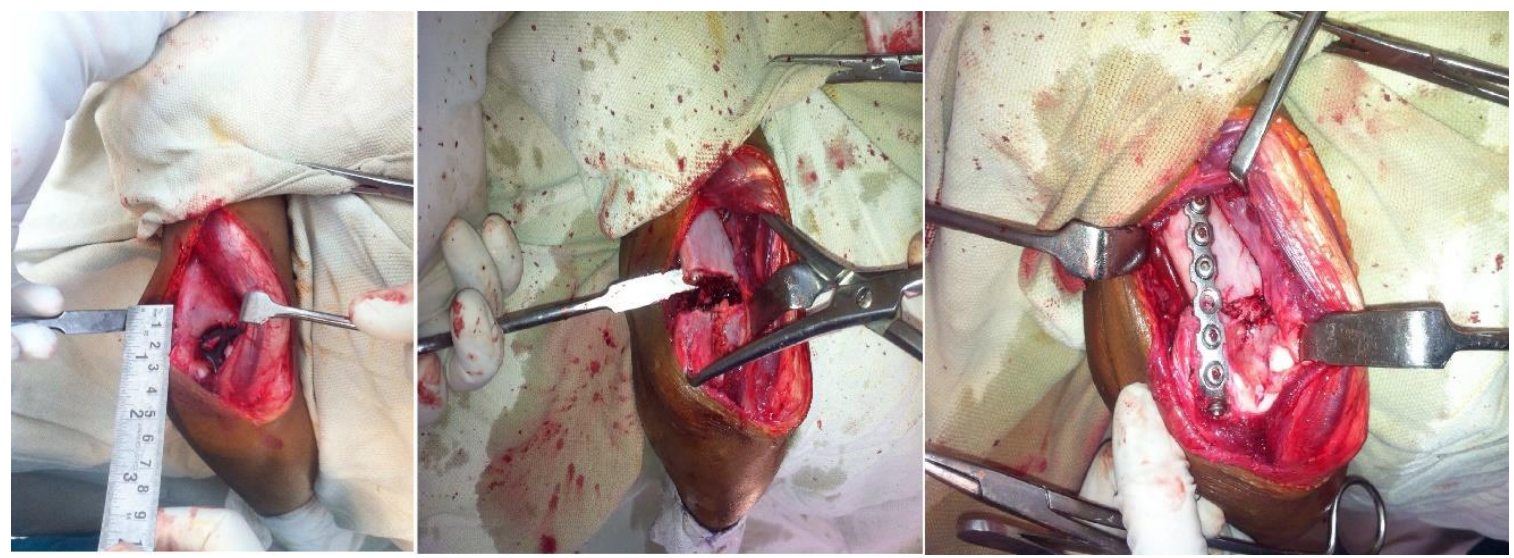

Fig. 1

severity of deformity. The lateral condyle prominence was also measured in these patients.

Preoperative radiographs of both the upper limbs in full supination and extension were analysed for severity of deformity. (Humerus -elbow- wrist angle). (Fig. 1) Lateral prominence index was measured in both preoperative radiograph and last follow up radiograph. (Fig. 2) Rotational deformity was measured by physical examination in which the angle between the forearm and the back was measured with the elbow in $90^{\circ}$ flexion and the shoulder in hyperextension.

The amount of wedge to be removed on the affected side was measured preoperatively by overlapping the flipped sketch of the affected side to the radiograph of unaffected side of same magnification on x-ray view box. The base of wedge to be removed was determined by the wedge of the affected sketch which was removed from the sketch till it coincided with the $\mathrm{x}$-ray of normal side. The Wong et $\mathrm{al}^{15}$ method was used to measure lateral prominence index in these patients (Fig. 2). All data regarding range of motion, neurovascular status were recorded preoperatively.

\section{Surgical Technique}

All patients were operated under general anaesthesia with patient in lateral position and affected side up with arm on arm rest. After proper draping, via posterior triceps reflecting approach, distal humerus was exposed subperiosteally posteriorly, laterally and anteriorly after identifying ulnar nerve on medial side. The osteotomy site and base of wedge were marked with scale. [Fig. 3] Distal cut of the osteotomy was kept parallel to the joint line while as superior cut was made obliquely to meet the inferior cut on medial side. The wedge was removed with the help of oscillating saw leaving the medial hinge intact. The osteotomy was completed manually and reduction done and held with pointed $\mathrm{AO}$ clamps. Correction of deformity was again confirmed peroperatively. Then fixation of the osteotomy was done with 6 or 7 whole reconstruction plate as per AO principles of fracture fixation. (Fig. 2) To increase the fracture stability in higher age group and in unstable osteotomy, medial column fixation was done with interfragmentary screw as per AO principles, care was taken not to injure ulnar nerve. Image intensifier was used to confirm the amount of correction achieved and fixation done before closure of wound. Wound was closed back in layers over a suction drain.

Wound was inspected on $2^{\text {nd }}$ postoperative day and drain was removed. Active and active assisted range of motion was started on $2^{\text {nd }}$ postoperative day as patient tolerated. A removable posterior splint was used for four weeks postoperatively. Follow up $\mathrm{x}$ rays were taken at $2,6,12$ weeks and at final follow up.

The recorded range of motion, union, carrying angle, lateral prominence index were measured at final follow- up and analysed.

\section{Results}

We had 14 young adult patients of post-traumatic cubitus varus operated in our hospital in last three years. The complete data of the all the patients are given in table 1 . The mean age of patients was 24.4 years and mean time since injury to correction of deformity was 18 years. The male and female ratio was equal. Our mean follow up was 21.42 months. The details of the all patients are given in table 1 . The mean cubitus varus deformity of $-15.42^{0}$ was corrected to a mean of cubitus valgus of $11.71^{\circ}$ and our mean valgus angle on normal side was $13^{\circ}$. The lateral condyle prominence was reduced from mean of 5.56 to mean of 13.14 percent. The mean elbow preoperative range of motion of $132^{\circ}$ was reduced to mean post operative range of motion of $115.35^{\circ}$. The mean time to union in our patients was 11.14 months. Union was said to occur when there was no pain on movements and when $\mathrm{x}$ rays shows trabeculae crossing the osteotomy site. One of the patients was operated again after 3 months because of gap non union at the osteotomy site. None of our patients had nerve injury or wound infection 
Table 1

\begin{tabular}{|c|c|c|c|c|c|c|c|c|c|c|}
\hline \multirow{2}{*}{$\begin{array}{l}\text { S. } \\
\text { No. }\end{array}$} & \multirow[t]{2}{*}{ Age/sex } & \multirow[t]{2}{*}{$\begin{array}{c}\text { Side } \\
\text { affected }\end{array}$} & \multicolumn{3}{|c|}{ Humerus elbow wrist angle } & \multicolumn{2}{|c|}{ ROM } & \multicolumn{2}{|c|}{$\begin{array}{c}\text { Lat prominence } \\
\%\end{array}$} & \multirow{2}{*}{$\begin{array}{c}\text { Union } \\
\text { achieved } \\
\text { (Weeks) }\end{array}$} \\
\hline & & & $\begin{array}{l}\text { Affected } \\
\text { side }\end{array}$ & Normal side & $\begin{array}{c}\text { Post } \\
\text { operative }\end{array}$ & Pre op & Post op & Pre op & Post op & \\
\hline 1 & $\mathrm{~F} / 17$ & $\mathrm{R}$ & -16 & 12 & 10 & $0-130$ & $10-115$ & 4.5 & -21 & 10 \\
\hline 2 & $\mathrm{M} / 22$ & $\mathrm{R}$ & -10 & 8 & 8 & $0-135$ & $5-120$ & 7 & -5 & 11 \\
\hline 3 & $\mathrm{~F} / 19$ & $\mathrm{~L}$ & -12 & 14 & 12 & $-10-140$ & $10-120$ & 3.6 & -15 & 9 \\
\hline 4 & $\mathrm{M} / 29$ & $\mathrm{R}$ & -18 & 12 & 14 & $10-125$ & $15-110$ & 6 & -6 & 12 \\
\hline 5 & $\mathrm{M} / 25$ & $\mathrm{~L}$ & -26 & 10 & 6 & $0-120$ & $10-110$ & 7.5 & -7 & 13 \\
\hline 6 & $\mathrm{~F} / 18$ & $\mathrm{~L}$ & -14 & 16 & 14 & $-10-138$ & $0-120$ & 5.2 & -17 & 10 \\
\hline 7 & $\mathrm{~F} / 16$ & $\mathrm{R}$ & -18 & 12 & 14 & $0-130$ & $10-110$ & 5.6 & -15 & 8 \\
\hline 8 & $\mathrm{M} / 32$ & $\mathrm{~L}$ & -24 & 6 & 4 & $10-120$ & $20-110$ & 8 & -8 & 12 \\
\hline 9 & $\mathrm{M} / 27$ & $\mathrm{~L}$ & -12 & 18 & 14 & $-10-130$ & $10-130$ & 6.5 & -9 & 12 \\
\hline 10 & $\mathrm{M} / 32$ & $\mathrm{R}$ & -10 & 22 & 18 & 0-135 & $0-130$ & 5.5 & -11 & 14 \\
\hline 11 & $\mathrm{~F} / 21$ & $\mathrm{R}$ & -6 & 16 & 16 & $0-140$ & $0-140$ & 3 & -18 & 10 \\
\hline 12 & $\mathrm{~F} / 26$ & $\mathrm{~L}$ & -16 & 12 & 12 & $-10-130$ & $0-130$ & 4.3 & -16 & 11 \\
\hline 13 & $\mathrm{~F} / 29$ & $\mathrm{~L}$ & -20 & 16 & 16 & $10-135$ & $10-130$ & 5.2 & -24 & 12 \\
\hline 14 & $\mathrm{M} / 30$ & $\mathrm{~L}$ & -14 & 8 & 6 & $0-130$ & $0-130$ & 6 & -12 & 12 \\
\hline Mean & 24.4 & & -15.42 & 13 & 11.71 & 132 & 115.35 & 5.56 & -13.14 & 11.14 \\
\hline
\end{tabular}

\section{Discussion}

This is a retrospective study conducted on fourteen operated patients of cubitus varus deformity corrected by lateral closing wedge osteotomy and rigid lateral column fixation. Since our seventy percent of population belong to villages and bone setter practices are very common in this part of the world, we operate various neglected trauma patients presenting late to our hospital. Most of these patients report early before the skeletal maturity for correction of the deformity except a few unprivileged cases who present late during early adulthood. Young females with post-traumatic cubitus varus come for correction of the deformity as it becomes cosmetically unacceptable to wear sleeveless or half sleeves. While as male patients with such deformities are usually forced to undergo correction of the deformity to obtain physical fitness for recruitment in various physically demanding jobs. A well accepted fact is that post-traumatic cubitus varus deformity doesn't interfere with functions of elbow. So correction of such deformity is for pure cosmetic reasons. In skeletally immature bones various procedures used are medial open wedge osteotomy and lateral closing wedge osteotomy. More advanced procedures advocated are step cut translational osteotomy and dome osteotomy., ${ }^{9,10}$ But lateral closing wedge osteotomy is proffered in adult cubitus varus deformity. ${ }^{16}$ Advantage of lag screw fixation and wide area of contact in oblique osteotomy have some additional benefits. ${ }^{17}$ Stabilisation of lateral closing wedge osteotomy may differ depending upon method of fixation and implants used for fixation. Cubitus varus deformity correction in skeletally mature patients is demanding procedure due to mature skeleton, increased instability at osteotomy site, chances of delayed or non-union and postoperative decrease in range of elbow motion. ${ }^{18}$

Only few studies on adult cubitus varus correction with different techniques of fixation are there in literature. In study by Matsushita et al doing arc osteotomy in three post pubertal patients with mean age of 20 years with 6 to 8 weeks of cast immobilisation after pining the osteotomy site. Total arc of motion reduced in two of his three patients by 40 and 10 degrees. ${ }^{19}$ In our study where we use rigid fixation of lateral closing wedge osteotomy, the mean loss of arc of motion were $15.65^{\circ}$. Tienet et al ien his study of dome osteotomy olecranon osteotomy was done for two skeletally immature bones and plate was applied posteriorly. 20 to 30 degrees of rang of motion was lost on final followup. ${ }^{7}$ Three dimensional osteotomy on 23 consecutive patients by Chung et al was followed by one nerve palsy with pinning and one myositis ossificans was reported. No such complication was observed in our study. $3 \%$ to $6 \%$ deficit in peak triceps torque was reported in triceps splitting approach. This approach was used by Kim et al while using Y plate posteriorly in step cut osteotomy. The results of our study for correction of cubitus varus deformity in adult by lateral closed wedge osteotomy and posterior plating through posterior triceps retracting approach were promising. The bone resection in lateral closing wedge osteotomy is more compared to step cut translational ${ }^{11}$ and transverse closing wedge osteotomy. ${ }^{9}$ The length of humerus is maintained in dome osteotomy. ${ }^{7,20}$ In our experience, shortening of the humerus was not detectable clinically in most cases after correction of the deformity. The osteotomy gap on medial side my develop if deformity is more and large resection of bone is required. No such technical difficulty was observed in our case series. Fracture healing varies from patient to patient of different age groups as indicated in various animal studies. ${ }^{21,22}$ The susceptibility to stiffness is more in adults than in children. ${ }^{23,24}$ Due to longer recovery, adultsareaslo more prone to develop stiffness. The mean loss of $15.65^{0}$ arc of motion was noted in our fourteen cases.

\section{Conclusion}

Neglected traumatic deformity like cubitus varus must be dealt early to avoid complications. Lateral closing wedge osteotomy with rigid fixation of lateral column of distal humerus for correction of cubitus varus in young skeletally mature adults has promising results in achieving the 
correction of deformity, timely union and preserving the elbow arc of motion.

\section{Conflict of Interest: None.}

Financial Support: No financial support was received for this study.

\section{References}

1. Bellemore MC, Barrett IR, Middleton RW, Scougall JS, Whiteway DW. Supracondylar osteotomy of the humerus for correction of cubitus varus. J Bone Joint Surg Br 1984;66:56672.

2. Devnani AS. Lateral closing wedge supracondylar osteotomy of humerus for post-traumatic cubitus varus in children. Injury 1997;28:643-7.

3. Butt MF, Dhar SA, Farooq M, Kawoosa AA, Mir MR. Lateral invaginating peg (LIP) osteotomy for the correction of posttraumatic cubitus varus deformity. J Pediatr Orthop $B$ 2009;18(5):265-70.

4. King D, Secor C. Bow elbow (cubitus varus). J Bone Joint Surg Am 1951;33:572-6.

5. Kanaujia RR, Ikuta Y, Muneshige H, Higaki T, Shimogaki K. Dome osteotomy for cubitus varus in children. Acta Orthop Scand 1988;59:314-7.

6. Pankaj A, Dua A, Malhotra R, Bhan S. Dome osteotomy for posttraumatic cubitus varus: a surgical technique to avoid lateral condylar prominence. J Pediatr Orthop 2006;26:61-6.

7. Tien YC, Chih HW, Lin GT, Lin SY. Dome corrective osteotomy for cubitus varus deformity. Clin Orthop Relat Res 2000;380:158-66.

8. Laupattarakasem W, Mahaisavariya B, Kowsuwon W, Saengnipanthkul S. Pentalateral osteotomy for cubitus varus: clinical experiences of a new technique. J Bone Joint Surg Br 1989;71:667-70

9. Chung MS, Baek GH. Three-dimensional corrective osteotomy for cubitus varus in adults. J Shoulder Elbow Surg 2003;12:472-5.

10. Uchida Y, Ogata K, Sugioka Y. A new three-dimensional osteotomy for cubitus varus deformity after supracondylar fracture of the humerus in children. J Pediatr Orthop 1991;11:327-31.

11. Kim HT, Lee JS, Yoo CI. Management of cubitus varus and valgus. J Bone Joint Surg Am 2005;87:771-80.

12. Kumar K, Sharma VK, Sharma R, Maffulli N. Correction of cubitus varus by French or dome osteotomy: a comparative study. J Trauma 2000;49:717-21.

13. Kinik H, Atalar H, Mergen E. Management of distal humerus fractures in adults. Arch Orthop Trauma Surg 1990;119:467-9.

14. Helfet DL, Kloen P, Anand N, Rosen HS. Open reduction and internal fixation of delayed unions and nonunions of fractures of the distal part of the humerus. J Bone Joint Surg Am 2003;85:33-40.

15. Wong HK, Lee EH, Balasubramaniam P. The lateral condylar prominence: a complication of supracondylar osteotomy for cubitus varus. J Bone Joint Surg Br 1990;72:859-61.

16. S. Pandey. Cubitus varus in adults correction with lateral closing wedge osteotomy and fixation with posterior plating. $J$ Coll Med Sci Nepal 2012;8(2):49-53.

17. Rayhack JM. Ulnar shortening. Tech Hand Up Extrem Surg 2003;7:52-60.

18. Hyun Sik Gong, Moon Sang Chung, Joo Han Oh, Hoyune Esther Cho, and Goo Hyun Baek. Oblique Closing Wedge Osteotomy and Lateral Plating for CubitusVarus in Adults. Clin Orthop Relat Res 2008;466(4):899-906.

19. T. Matsushita, A. Nagano. Arc osteotomy of the humerus to cor-rectcubitusvarus. Clin Orthop Relat Res 1997;336:111-5.
20. Pankaj A, Dua A, Malhotra R, Bhan S. Dome osteotomy for posttraumatic cubitus varus: a surgical technique to avoid lateral condylar prominence. J Pediatr Orthop 2006;26:61-6.

21. Lu C, Miclau T, Hu D, Hansen E, Tsui K, Puttlitz C, Marcucio RS. Cellular basis for age-related changes in fracture repair. $J$ Orthop Res 2005;23:1300-7.

22. Meyer RA Jr, Tsahakis PJ, Martin DF, Banks DM, Harrow ME, Kiebzak GM. Age and ovariectomy impair both the normalization of mechanical properties and the accretion of mineral by the fracture callus in rats. $J$ Orthop Res 2001;19:428-35.

23. Hart GM, Wilson DW, Arden GP. The operative management of the difficult supracondylar fracture of the humerus in the child. Injury 1977;9:30-4.

24. Papandrea R, Waters PM. Posttraumatic reconstruction of the elbow in the pediatric patient. Clin Orthop Relat Res 2000;370:115-26.

How to cite this article: Gul S, Kamal Y, Ahmed J, Ali MF, Lone BA. Cubitus varus deformity in young adults, Correction by rigidly fixed lateral closing wedge osteotomy. Indian J Orthop Surg 2019;5(2):141-4. 